\title{
ASSESSMENT OF SHOULDER JOINT STRENGTH DISPROPORTION OF MASTERS SWIIMMERS
}

\author{
Aleksander Wiażewicz, ${ }^{A, B, C, D}$ Jerzy Eider ${ }^{A, D}$ \\ Faculty of Physical Culture and Health Promotion, University of Szczecin, Poland \\ A Study Design; ${ }^{\mathrm{B}}$ Data Collection; ${ }^{\mathrm{C}}$ Statistical Analysis; ${ }^{\mathrm{D}}$ Manuscript Preparation \\ Address for correspondence: \\ Aleksander Wiażewicz \\ Faculty of Physical Culture and Health Promotion, University of Szczecin \\ Al. Piastów 40 B, building 6, 71-065 Szczecin, Poland \\ E-mail: Aleksander.Wiazewicz@usz.edu.pl
}

\begin{abstract}
Ahstract The aim of this study was to find out whether Masters class swimming affects strength disproportion and if there is a correlation between the length of sport swimming training in Masters swimmer's past (SST) and strength parameter's deficits? Eighteen Masters category swimmers affiliated in Szczecin Masters Team (178.3 $\pm 2.28 \mathrm{~m} ; 77.9 \pm 2.86 \mathrm{~kg})$ participated in the study. Isokinetic strength measurement was made on Biodex S4 dynamometer. Subjects performed shoulder flexion/extension moves: 3 repetitions - $60 \mathrm{deg} / \mathrm{sec}$ and 20 repetitions $-180 \mathrm{deg} / \mathrm{sec}$. Following values were used: peak torque (PT), maximal repetition work (MRW), coefficient of variation (COV), total work (TW), average power (AP), agonist to antagonist ratio (AG:AN). None of the investigated variables were statistically significant in side to side comparison. All of the parameters were higher in extension. Also, no statistically significant difference between sides in AG:AN. Moderate positive correlation was found between SST and PT deficit in extension movement (0.420). Also low positive correlation between SST and PT deficit in flexion (0.396), and MRW deficit in extension (0.352). Masters class swimming did not affect side strength disproportion or agonist to antagonist differences. However, it is possible that swimming training in other categories does.
\end{abstract}

Key WOrlls shoulder joint, strength, Masters swimmers, Biodex

\section{Introduction}

The number of masters athletes is increasing. They spend more time working out, playing sport and have better health then other people (Rittwager, di Prampero, Maffulli, Narici, 2009). Masters athletes are active, full of power and vital forces. They want to live a healthy, fulfilled life (Dionigi, 2006). The effects of regular Masters trainings provide that the older athletes perform much better than younger people that lead sedentary lives (Ransdell, Vener, Huberty, 2009). Researchers Young and Medic (2011) were also examining social influences on the sport commitment of Masters swimmers. Hodge, Allen, Smellie (2008) studied the relationships amongst achievement goals, social goals and motivational correlates in Masters sport. Others Petrescu, Piţigoi, Păunescu (2014) are highlighting the role and influence of Masters swimming on mental condition. 
However, the question arises whether Masters sport swimming is certainly good for older athletes strength and health? Abrahin's et al. (2016) results showed that swimming has no positive influence on bone mineral density. Banias and Rasadean (2011) highlighted the reduction of swimming speed in relation to age, in freestyle men events. Muscle area decreases by $40 \%$ in the ages section between 20 and 80 years. Decreased power, lower force production and less efficient agonist-antagonist muscle group coordination is observed (Lemmer et al., 2003). Nevertheless the strength abilities are very important element that has an impact on the final swimming result (Crowe, Babington, Tanner, Stager, 1999; Dopsaj, Matković, Thanopoulos, Okičić, 2004; Kjendlie, Thorsvald, 2006; Morouco et al., 2011). Numerous repeats can cause an imbalance in muscle strength of the shoulder girdle (Bak, 1996). Batalha, Marmeleira, Garrido, Silva (2014), Batalha, Raimundo, Tomas-Carus, Barbosa, Silva (2013), Ramsi, Swanik, Swanik, Straub, Mattacola (2004) and Walker, Gabbe, Wajswelner, Blanch, Bennell (2012) indicate that swimming technique can cause a lack of balance in shoulder muscle strength. Olivier, Quintin, Rogez (2008) formulated a conclusion that sport swimming at the highest level weakens the shoulder joint and interferes muscle balance. Havriluk (2009) identified three factors limiting the effectiveness of swimming: the differences between the right and left shoulder, loss of strength and unnecessary movements. These factors may affect all swimmers.

The main aim of this study was to find out whether Masters class swimming affects side strength disproportion or agonist to antagonist differences?

The purpose was to find statistically significant differences in: peak torque, work done in maximal repetition, repeatability of movements, total work done and average power between the right and the left arm in flexion and extension in Masters swimmers. Furthermore it was to find out significant differences in agonist to antagonist strength ratios of their right and left shoulder and a correlation between the length of sport swimming training in Masters swimmer's past and strength parameter's deficits.

\section{Methods}

Eighteen subjects (178.3 $\pm 2.28 \mathrm{~m} ; 77.9 \pm 2.86 \mathrm{~kg}$ ) participated in the study. They were all Masters category swimmers affiliated in Szczecin Masters Team. Participants gave written consent to the test. Bioethics Committee at the Regional Medical Chamber in Szczecin has expressed a positive opinion about the research project in the following range (resolution No. 15/KB/V/2013 dated 10.12.2013). At first, subjects performed 5-minute warm up on the cross trainer device, then 5-minute warm up focused on the shoulder joint. The isokinetic strength measurement was made on the Biodex S4 dynamometer (Biodex Corp., Shirley, NY, USA). During the test, subjects done 3 shoulder flexion/extension repetitions with the $60 \mathrm{deg} / \mathrm{sec}$ angular speed (protocol 1). After 2-minute break they performed 20 shoulder flexion/extension repetitions with the $180 \mathrm{deg} / \mathrm{sec}$ angular speed (protocol 2). There was a 4-minute rest between right and left limb measurement. Preparation part and the measurement were made in accordance with instructions (Biodex Medical Systems, Inc. Biodex Multi-Joint System - Pro. Setup/Operation Manual.).

The following values were used: peak torque (PT), maximal repetition work (MRW) from protocol 1 and coefficient of variation (COV), total work (TW), average power (AP), agonist to antagonist ratio (AG:AN) form protocol 2 (for both - flexion and extension).

For statistical data analyzing a Statistica 12.5 and descriptive statistics tools were used. To check whether samples came from a normally distributed population, researchers used a Shapiro-Wilk test. If the result of ShapiroWilk's test was significant (significance level 0.05 ) in at least one of the two compared variables, a nonparametric 
Mann-Whitney $U$ test was used. Otherwise a t-Test: two-sample assuming equal variances data analysis tool (significance level 0.05) was used. Pearson correlation coefficients were computed between the length of sport swimming training (SST) in the subjects' past and PT, MRW, TW and AP side deficits.

\section{Results}

Only one parameter difference - COV, was close to statistically significant. PT and COV were higher in right shoulder in both moves. MRW, TW and AP were higher in the left arm in both directions. But none of the investigated variables were statistically significant in side to side comparison. All of the parameters were higher in extension moves (Table 1). Left shoulder had higher agonist to antagonist strength ratio, but also there was no statistically significant difference between sides (Table 2).

Tahle 1. Differences in right and left shoulder joint strength in Masters swimmers

\begin{tabular}{|c|c|c|c|c|c|}
\hline & \multirow{2}{*}{ Variable } & \multicolumn{2}{|c|}{ Flexion } & \multicolumn{2}{|c|}{ Extension } \\
\hline & & Average $\pm S D$ & $P$ & Average \pm SD & $P$ \\
\hline \multirow{2}{*}{$\mathrm{PT}(\mathrm{Nm})$} & right shoulder & $56.39 \pm 4.18$ & \multirow{2}{*}{0.9152} & $65.25 \pm 5.80$ & \multirow{2}{*}{0.8615} \\
\hline & left shoulder & $55.77 \pm 4.02$ & & $63.85 \pm 5.45$ & \\
\hline \multirow{2}{*}{ MRW (J) } & right shoulder & $154.88 \pm 11.85$ & \multirow{2}{*}{0.9502} & $174.68 \pm 16.04$ & \multirow{2}{*}{0.9248} \\
\hline & left shoulder & $155.88 \pm 10.59$ & & $176.72 \pm 14.23$ & \\
\hline \multirow{2}{*}{$\operatorname{cov}(\%)$} & right shoulder* & $15.76 \pm 2.02$ & \multirow{2}{*}{0.0556} & $20.92 \pm 3.31$ & \multirow{2}{*}{0.5166} \\
\hline & left shoulder* & $10.97 \pm 0.91$ & & $16.39 \pm 2.23$ & \\
\hline \multirow{2}{*}{ TW (J) } & right shoulder & $1,663.82 \pm 150.63$ & \multirow{2}{*}{0.8955} & $1,803.26 \pm 261.71$ & \multirow{2}{*}{0.7036} \\
\hline & left shoulder & $1,691.79 \pm 148.22$ & & $1,934.58 \pm 220.59$ & \\
\hline \multirow{2}{*}{$\mathrm{AP}(\mathrm{W})$} & right shoulder & $53.04 \pm 5.55$ & \multirow{2}{*}{0.7205} & $59.17 \pm 9.33$ & \multirow{2}{*}{0.6962} \\
\hline & left shoulder & $55.86 \pm 5.49$ & & $64.06 \pm 8.19$ & \\
\hline
\end{tabular}

${ }^{*}$ A nonparametric Mann-Whitney U test was used.

Table 2. Differences of agonist to antagonist strength ratio in Masters swimmers shoulder joint

\begin{tabular}{llcc}
\hline & Variable & Average \pm SD & P \\
\hline AG:AN $(\%)$ & right shoulder* & $87.92 \pm 16.52$ & 0.937 \\
& left shoulder* & $89.21 \pm 18.48$ & \\
\hline
\end{tabular}

${ }^{*}$ A nonparametric Mann-Whitney $U$ test was used.

The length of sport swimming training (SST) in the subjects' past was compared with PT, MRW, TW and AP side deficits. Moderate positive correlation was found between SST and PT deficit in extension movement (0.420). Low positive correlation was found between SST and PT deficit in flexion (0.396), also MRW deficit in extension (0.352) (Table 3).

Table 3. Correlations between length of sport swimming training (SST) in the subjects' past and measured variables deficits

\begin{tabular}{lcccccccc}
\hline \multirow{2}{*}{ Variables } & \multicolumn{4}{c}{ Flexion } & \multicolumn{4}{c}{ Extension } \\
\cline { 2 - 9 } & PT def. & MRW def. & TW def. & AP def. & PT def. & MRW def. & TW def. & AP def. \\
\hline SST & 0.396 & 0.008 & -0.164 & -0.146 & 0.420 & 0.352 & 0.057 & 0.097 \\
\hline
\end{tabular}




\section{Discussion}

There are no statistically significant differences in: peak torque, work done in maximal repetition, total work done and average power between the right and the left arm in flexion and extension in Masters swimmers. Also, no difference in dominant and non-dominant shoulder motor function was seen in either the younger or older untrained men in Gallagher, Zuckerman, Cuomo, Ortiz (1996) research. Subjects in this studies had higher PT scores than untrained persons results: extension $53.9 \mathrm{Nm}$ and flexion $43.5 \mathrm{Nm}$ (Ivey, 1985). Study was carried out on Cybex. As well as PT was higher than average presented by Mayer (2001) $48 \mathrm{Nm}$ in flexion, $62 \mathrm{Nm}$ in extension, both measured in $60 \mathrm{deg} / \mathrm{sec}$.

All isokinetic variables were higher in the extension movements, for both sides. This is consistent with the Alonso-Cortés Fradejas et al. (2006) results. Also Ivey (1985) results indicates that in untrained persons shoulder strength extension results were higher than in flexion in $60 \mathrm{deg} / \mathrm{s}$ test. In individual analysis of subjects results, there were notable differences and large variables deficits. Masters athletes should accept that they will not achieve the same level as they did when they were younger. Aging will cause changes in the body as well as in their ability to compete. Weight training prevention program should be applied to avoid the lean body mass loss and strength decline (Ransdell et al., 2009). According to Alonso-Cortés Fradejas et al. (2006) sport swimming participants should seek for a harmonious development of both sides of the body.

The repeatability of movements - coefficient of variances was high, but also no statistically significant difference was noticed between the right and left shoulder. Acceptable COV is less than or equal to 15\% (Isokinetic testing and data interpretation) as in the extension in subjects results. COV of shoulder flexion was just above this limit. Ransdell et al. (2009) indicates that the quantity of training can't be more important than its quality.

The agonist to antagonist strength ratios of Masters swimmers are higher than suggested by Biodex $-83 \%$ (Isokinetic testing and data interpretation), but there is no significant difference between right and left shoulder. The AG:AN ratio is important information in pathological states, and its normalization must be the main goal of rehabilitation (Codine, Bernard, Pocholle, Herisson, 2005). Misalignment of AG:AN ratio can lead to injuries (Isokinetic testing and data interpretation). Many authors (Batalha et al., 2014; Batalha et al., 2013; Ramsi et al., 2004; Walker et al., 2012; Wiażewicz, 2015) postulates enforcement of compensatory programs, because of the agonist to antagonist ratio disorder.

There were moderate and low positive correlations between length of sport swimming training in the subjects' past and measured variables deficits. Although swimming is symmetrical sports, long-term and intensive water training, causes asymmetry targeted to the stronger arm (Olivier et al., 2008). The results of Batalha et al. (2014) also suggests that swimming training macrocycles lead to an increase of the shoulder rotator muscles imbalance in younger swimmers.

\section{Conclusion}

Masters class swimming did not affect side strength disproportion or agonist to antagonist differences. However, it is possible that swimming training in other categories does. It should be considered to perform a similar study with sport swimmers from other categories with high training experience. 


\section{References}

Abrahin, O., Rodrigues, R.P., Marçal, A.C., Alves, E.A.C., Figueiredo, R.C., de Sousa, E.C. (2016). Swimming and cycling do not cause positive effects on bone mineral density: a systematic review. Revista Brasileira de Reumatologia (English Edition), 56 (4), 345-351.

Alonso-Cortés Fradejas, B., Alvear-Órdenes, I., Ramírez-García, C., García-Isla, F.J., González-Gallego, J., Seco Calvo, J. (2006). Valoración isocinética del hombro en jóvenes nadadores mediante un patrón diagonal. Fisioterapia, 28 (6), $298-307$.

Bak, K. (1996). Nontraumatic glenohumeral instability and coracoacromial impingement in swimmers. Scandinavian Journal of Medicine and Science in Sports, 6 (3), 132-144.

Banias, P., Rasadean, M. (2011). Study on reduction of swimming speed in relation to age, in freestyle men events, in masters swimming. Procedia - Social and Behavioral Sciences, 15, 2684-2688.

Batalha, N., Marmeleira, J., Garrido, N., Silva, A.J. (2014). Does a water-training macrocycle really create imbalances in swimmers' shoulder rotator muscles? European Journal of Sport Science, 23, 1-6.

Batalha, N.M., Raimundo, A.M., Tomas-Carus, P., Barbosa, T.M., Silva, A.J. (2013). Shoulder rotator cuff balance, strength, and endurance in young swimmers during a competitive season. Journal of Strength and Conditioning Research, 27 (9), $2562-2568$

Biodex Medical Systems, Inc. Biodex Multi-Joint System - Pro. Setup/Operation Manual. New York: Biodex Medical Systems, Inc.

Biodex Medical Systems, Inc. Isokinetic testing and data interpretation. New York: Biodex Medical Systems, Inc.

Codine, P., Bernard, P.L., Pocholle, M., Herisson, C. (2005). Évaluation et rééducation des muscles de l'épaule en isocinétisme: méthodologie, résultats et applications. Annales de Réadaptation et de Médecine Physique, 48 (2), 80-92.

Crowe, S., Babington, J., Tanner, D., Stager, J. (1999). The relationship of strength to dryland power, swimming power, and swimming performance. Med Sci Sports Exerc, 31 (5), S255.

Dionigi, R. (2006). Competitive sport as leisure in later life: negotiations, discourse, and aging. Leis Sci, 28, 181-196.

Dopsaj, M., Matković, I., Thanopoulos, V., Okičić, T. (2004). Reliability and validity of basic kinematics and mechanical characteristics of pulling force in swimmers measured by method of tethered swimming with maximum intensity of 60 seconds. Physical Education and Sport, 1 (10), 11-22.

Gallagher, M.A., Zuckerman, J.D., Cuomo, F., Ortiz J. (1996). The effect of age, speed, and arm dominance on shoulder function in untrained men. Journal of Shoulder and Elbow Surgery, 5 (1), 25-31.

Havriluk, R. (2009). Analyzing Hand Force in Swimming. Three Typical Limiting Factors. ASCA Newsletter, 5, 22-26.

Hodge, K., Allen, J.B., Smellie, L. (2008). Motivation in Masters sport: Achievement and social goals. Psychology of Sport and Exercise, 9 (2), 157-176.

Ivey, F.M., Calhoum, J.H., Rusche, K., Bierschenk, J. (1985). Isokinetic testing of shoulder strength/normal values. Arch Phys Med Rehabil, 66, 384-386.

Kjendlie, P.-L., Thorsvald, K. (2006). A tethered swimming power test is highly reliable. Port J Sport Sci, 6 (S2), $231-233$.

Lemmer, J.T., Hurlbut, D.E., Martel, T.B.L., Ivey, F.M., Metter, E.J., Fozard, J.L., Fleg, J.L., Hurley B.F. (2003). Age and gender responses to strength training and detraining. Med Sci Sports Exerc, 32, 1505-1512.

Mayer, F., Horstman, T. (2001). Diagnostics with isokinetic devices in shoulder measurements - potentials and limits. Isokinet Exerc Sci, 9, 19-25.

Morouco, P., Neiva, H., Gonzalez-Badillo, J., Garrido, N., Marinho, D., Marques, M. (2011). Associations Between Dry Land Strength and Power Measurements with Swimming Performance in Elite Athletes: a Pilot Study. J Hum Kinet, 29A, 105-112.

Olivier, N., Quintin, G., Rogez, J. (2008). The high level swimmer articular shoulder complex. Annales de Readaptation et de Medecine Physique, 51 (5), 342-347.

Petrescu, S., Piţigoi, G., Păunescu, M. (2014). The Effects of Practicing Swimming on the Psychological Tone in Adulthood. Procedia Social and Behavioral Sciences, 159, 74-77.

Ramsi, M., Swanik, K.A., Swanik, C., Straub, S., Mattacola, C. (2004). Shoulder-Rotator Strength of High School Swimmers over the Course of a Competitive Season. Journal of Sport Rehabilitation, 13 (1), 9-18.

Ransdell, L.B., Vener, J., Huberty J. (2009). Masters Athletes: An Analysis of Running, Swimming and Cycling Performance by Age and Gender. Journal of Exercise Science \& Fitness, 7 (2), S61-S73.

Rittwager, J., di Prampero, P.E., Maffulli, N., Narici, M.V. (2009). Sprint and endurance power and aging: an analysis of master athletic world records. Proc $R$ Soc $B, 276,683-689$. 
Walker, H., Gabbe, B., Wajswelner, H., Blanch, P., Bennell, K. (2012). Shoulder pain in swimmers: A 12-month prospective cohort study of incidence and risk factors. Physical Therapy in Sport, 13 (4), 243-249.

Wiażewicz, A. (2015). Izokinetyczna ocena parametrów siłowych u zawodników w Ośrodku Szkolenia Pływackiego w Szczecinie. In: J. Eider (ed.), Wybrane zagadnienia olimpijskie w teorii i praktyce (pp. 197-213). Szczecin: Wydawnictwo Naukowe Uniwersytetu Szczecińskiego.

Young, B.W., Medic, N. (2011). Examining social influences on the sport commitment of Masters swimmers. Psychology of Sport and Exercise, 12 (2), 168-175.

Cite this article as: Wiażewicz, A., Eider, J. (2016). Assessment of Shoulder Joint Strength Disproportion of Masters Swimmers. Central European Journal of Sport Sciences and Medicine, 16 (4), 85-90. DOI: 10.18276/cej.2016.4-09. 